\title{
Anniversary Meeting of the Royal Society.
}

\section{$S^{I R}$}

R ERNEST RUTHERFORD completed his term of office as president of the Royal Society by a noteworthy address on the Society's policy for the promotion of research, before he presented the medals for 1930 at the anniversary meeting on Dec. 1 .

Looking back over the years since the end of the War, Sir Ernest pointed out how the responsibilities and work of the Society have increased during that period. Between 1919 and 1923, the Society received bequests under the wills of Miss Agnes Foulerton, Dr. Rudolph Messel, and Dr. Ludwig Mond, and a notable benefaction from Sir Alfred Yarrow. Foulerton and Yarrow research professorships were in due course instituted, and regulations for the Messel and Mond funds were adopted, subject to periodical review, which provided for further professorships as the need and opportunity might arise.

The Council of the Royal Society has watched the effect of thus endowing research professorships and is satisfied that the experiment, in Sir Ernest's words, " has proved an unqualified success". The appointments have added materially to the strength of the research side of the universities where the Royal Society professors are working, and "have led to a marked increase in the research power of the nations ". While it would be unwise to increase their number unduly in the near future, the Council has decided that the Messel and Mond funds can now be employed to the benefit of the whole body of science by supporting the work carried out in recent years by Dr. P. Kapitza, fellow of Trinity College, Cambridge, who has accordingly been appointed to a Messel professorship.

The funds held in trust by the Royal Society now amount to more than $£ 600,000$. Plans for the utilisation of the income from these funds have been carefully matured during the past ten years, for it was difficult to foresee the financial commitments of the Society due to its existing activities. The increased volume of publication after the War and the disproportionate increase of costs involved heavy expenditure, which the Council felt was justified in the interests of scientific research, but it has now been decided that the price of the Society's publications to outside subscribers must be increased. This will release a substantial sum which can be devoted to other purposes. It is now felt, however, that the time and opportunity have come to expend some of the accumulated income of the Society's trust funds, with the result that the sum of $\$ 15,000$ has been offered to the University of Cambridge for the purpose of building a cryogenic laboratory for the continuance of Dr. Kapitza's researches on the magnetic properties of materials at very low temperatures. The circumstances of the offer and an outline of Dr. Kapitza's work are given in an extract from Sir Ernest Rutherford's address which appears elsewhere in this issue.

The Council's policy, Sir Ernest said, has been and will be to keep watch over the whole field of scientific activity, giving help where there is promise of important advances and where the right man is to hand. It is by the support of major fundamental researches, especially in their initial stages, that the Society can employ most effectively the research funds which it has at its disposal.

Sir Ernest Rutherford also referred to the institution of a new research fellowship, financed from the bequest of the late Mr. E. W. Smithson. The first award has been made to Dr. P. D. F. Murray. After a dis- tinguished undergraduate career in the University of Sydney, Dr. Murray spent two years in research work in the Department of Comparative Anatomy at Oxford, and since 1926 has been lecturer in zoology at the University of Sydney. Nearly all his work has been in the field of experimental embryology, and he has investigated with conspicuous success the factors which determine the differentiation and shaping of the limbs and other parts of the body. Dr. Murray proposes to examine the cellular differentiation of the developing chick, which underlies the coarser morphology, and he will work in the first instance at the Strangeways Research Laboratory in Cam. bridge.

Sir Ernest Rutherford announced at the anniversary meeting that it has been decided to increase the number of candidates recommended annually for election to the Society from fifteen to seventeen. The Council reports that during the past year the Society received $£ 8000$ for general purposes under the will of Sir Dawson Williams and $£ 500$ for research under the will of Col. G. H. Leathem. In addition to the Messel research professorship and the Smithson research fellowship referred to above, the following research appointments were made during the past year, the subject of research being given in brackets : Foulerton Research Fellow, Dr. A. S. Parkes (physiology of reproduction); Mackinnon Research Student, Miss M. E. J. Chandler (fossil fruits and seeds of tertiary and quaternary age); Moseley Research Students, Mr. G. S. Adair (proteins of blood) and Dr. J. K. Roberts (exchange of energy between gas atoms and solid surfaces); Lawrence Research Student, Lieut.-Col. E. C. G. Maddock (tuberculosis); Tyndal Mining Research Student, Mr. A. G. R. Whitehouse (loss of salts from the body in sweating and the passage of water through the skin with and without sweating). Through the bequest of the late Mrs. Sollas, the capital of the Moseley Fund has been increased to more than twice its former value, so an additional studentship has been created; the two studentships will be awarded for work in physics or chemistry and for biological work bearing on pathology respectively. The Tropical Diseases Committee, with the aid of the Anonymous Bequest Fund, has instituted a research into kala-azar in Mediterranean countries, which is being conducted by Dr. Saul Adler, of the Hebrew University of Jerusalem. Grants amounting to $£ 6002$ have been allotted from the general fund by the Government Grant Committee, and ten grants, amounting to $£ 1600$, have been made from the Government Publication Grant.

We print below extracts from the remarks made by the president on the recipients' scientific work at the presentation of medals.

\section{Presentation of Medals.}

\section{Copley Medal, awarded to Sir William Bragg.}

To the rapid advance of experimental physics in the last thirty years, Sir William Bragg has made conspicuous contributions by his pioneering researches in radioactivity, X-rays, and crystallography. He was the first to realise, in 1904, the characteristic difference to be expected in the nature of the absorption of the massive $a$-particle and the light $\beta$-particles expelled from radioactive substances. His experimental researches brought out clearly

No. 3188, VoL. 126] 
the rectilinear path of the a-particles and their limited range of travel. In collaboration with his students, he examined in detail the variation of the ionisation of the a-particle along its path and its absorption by different kinds of matter. In his researches in X-rays and $\gamma$-rays, he was impressed by the difficulty that these high frequency radiations behaved like projected corpuscles - a difficulty which has only been in part resolved to-day. Following the discovery by Laue of the diffraction of X-rays by crystals, he was the first to develop a method for showing that ordinary X-radiation gave bright lines superimposed on a continuous spectrum. This reflection method of studying the spectrum of $\mathrm{X}$-rays has proved of great importance to the development of knowledge. In the hands of Moseley, it supplied a means of showing that the atoms have all a similar structure, and that their properties are defined by a whole number. In the hands of Sir William Bragg and his son, Prof. W. L. Bragg, it has provided a powerful tool for unravelling the structure of crystals. In this important development, which has added widely to our knowledge, Sir William Bragg has taken an active part, not only by his own researches but also by the direction of an important school of research on this subject at the Royal Institution.

\section{Rumford Medal, awarded to Prof. P. Debye.}

Prof. Debye introduced and developed a theory of the specific heats of solids which is of fundamental importance. By it, for the first time, the main phenomena relating to specific heats and their variation with temperature were quantitatively explained. $\mathrm{He}$ has made important contributions to the theory of the scattering and reflection of X-rays. Independently of Compton, he put forward the quantum theory of the change of frequency due to the scattering of $\mathrm{X}$-rays - the Compton effect. $\mathrm{He}$ was one of the inventors of the powdered crystal method of X-ray crystal analysis. By his introduction of the idea of spatial quantisation and by his investigations relating to the electric and magnetic properties of molecules he did much to advance our understanding of radiation and molecular phenomena. In collaboration with Hückel, Debye has developed a theory to account for the properties of strong electrolytes which has many important applications.

\section{Royal Medal, awarded to Prof. O. W.} RICHARDSON.

In his earlier work, Richardson laid the foundation of thermionics. He was the first to study in detail the escape of electrons from hot bodies in a vacuum and to give the correct interpretation of the phenomena. His work on photo-electric emission was also of fundamental importance, and in it many of the now generally accepted ideas relating to interaction betwieen radiation and matter were suggested. Among many important contributions in other fields was the prediction and calculation of the gyromagnetic effect - the rotational torque accompanying the magnetisation of a rod. In addition, he has done important work on electron emission associated with chemical action. $\mathrm{He}$ and his students have contributed largely towards filling up the gap between the ultra-violet and $\mathrm{X}$-ray spectra. His main work in recent years has related to the hydrogen molecule, and has afforded a detailed test of the new quantum mechanics when applied to one of the simplest structures for which the old quantum mechanics breaks down.
Royal Medal, awarded to Prof. J. E. Marr.

At a time when fow believed it possible, Prof. Marr discerned a delicate time-scale in the Lower Palæozoic Rocks, chiefly in the Lake District and North Wales, and applied it to elucidating the development of life and earth-structure. After testing his results in Scandinavia and in Bohemia he was able to make further use of them in setting in order corresponding rocks in South Wales. He has worked out the structure, origin, and development of the mountains, lakes, and rivers in Lakeland and elsewhere in the north of England. His work in association with Dr. Harker on the metamorphism brought about by the great mass of granite of Shap Fell on the rocks into which it was injected has become classic, and has inspired the rapid advance now being made in kindred studies. Of recent years he has contributed largely to knowledge of the Cambridge district, and particularly of the Pleistocene deposits and their relation to early man there and in East Anglia generally.

\section{Davy Medal, awarded to Prof. R. Robinson.}

By his investigations of the chemistry of the alkaloids, Prof. Robinson has made notable additions to the knowledge of the structure of these complex substances, and by experiment extended by theoretical discussion he has strikingly indicated possible mechanisms of their formation in Nature. He has also carried out brilliant synthetical work in connexion with the colouring matters of flowers. His theoretical studies of the mechanism of organic reactions, in particular substitution in aromatic compounds, have led to results of great value in that they enable a very wide range of reactions to be considered from a common point of view.

\section{Darwin Medal, awarded to Prof. Johannes SCHMIDT.}

Dr. Johannes Schmidt is at the same time a distinguished oceanographer and a recognised research worker in genetics of animals and plants. The number and extent of the voyages in small research vessels which Dr. Schmidt has accomplished with success, his large and varied collections of the pelagic fauna and flora, and the remarkable series of observations made under his direction, on the physical and chemical phenomena of the sea, give him an undisputed place in the first rank of those scientific explorers whose labours have built up our knowledge of the oceans of the world. His researches on the life-history of the fresh-water eel and the discovery of its breeding places far out in the Atlantic are widely known. Dr. Schmidt's breeding experiments on the tropical fresh. water fish, Lebistes, carried out in the Carlsberg Physiological Laboratory at Copenhagen, are of much interest, whilst his investigations on the local races of the viviparous blenny (Zoarces viviparus L.) are of outstanding importance and originality.

\section{Hughes Medal, awarded to Sir Venkata Raman.}

Sir Venkata Raman is one of the leading authorities on optics, in particular on the phenomenon of the scattering of light. In this connexion, about three years ago he discovered that the light's colour could be changed by scattering. This had been predicted theoretically some time before, but in spite of search the change had not been found. The "Raman effect" must rank among the best three or four discoveries in experimental physics of the last decade. It has proved, and will prove, an instrument of great power in the study of the theory of solids. 